\title{
BMJ Open A multi-cohort consortium for GEnder- Sensitive Analyses of mental health trajectories and implications for prevention (GESA) in the general population in Germany
}

\author{
Juliane Burghardt (D) , ${ }^{1}$ Ana Nanette Tibubos, ${ }^{1}$ Danielle Otten, ${ }^{1}$ Elmar Brähler, ${ }^{1}$ \\ Harald Binder, ${ }^{2}$ Hans Grabe, ${ }^{3}$ Johannes Kruse, ${ }^{4}$ Karl Heinz Ladwig (D) , 5,6 \\ Georg Schomerus, ${ }^{7}$ Philipp S Wild, ${ }^{8,9,10}$ Manfred E Beutel ${ }^{1}$
}

To cite: Burghardt J,

Tibubos AN, Otten D, et al. A multi-cohort consortium for GEnder-Sensitive Analyses of mental health trajectories and implications for prevention (GESA) in the general population in Germany. BMJ Open 2020;10:e034220. doi:10.1136/ bmjopen-2019-034220

- Prepublication history for this paper is available online. To view these files, please visit the journal online (http://dx.doi. org/10.1136/bmjopen-2019034220).

Received 10 September 2019 Revised 10 December 2019 Accepted 22 January 2020

Check for updates

(C) Author(s) (or their employer(s)) 2020. Re-use permitted under CC BY-NC. No commercial re-use. See rights and permissions. Published by BMJ.

For numbered affiliations see end of article.

\section{Correspondence to} Dr Juliane Burghardt; Juliane.Burghardt@unihamburg.de

\section{ABSTRACT}

Introduction Mental health is marked by gender differences. We formed a multi-cohort consortium to perform GEnder-Sensitive Analyses of mental health trajectories and study their implications for prevention (GESA). GESA aims at (1) identifying gender differences regarding symptoms and trajectories of mental health over the lifespan; (2) determining gender differences regarding the prevalence, impact of risk and protective factors; and (3) determining effects of mental health on primary and secondary outcomes (eg, quality of life, healthcare behaviour and utilisation).

Methods and analysis We plan to perform secondary analyses on three major, ongoing, population-based, longitudinal cohorts (Gutenberg Health-Study (GHS), Study of Health in Pomerania (SHIP), Cooperative Health Research in the Augsburg Region (KORA)) with data on mental and somatic symptoms, medical assessments and diagnoses in north-east, middle and southern Germany ( $n>40000$ ). Meta-analytic techniques (using DataSHIELD framework) will be used to combine aggregated data from these cohorts. This process will inform about heterogeneity of effects. Longitudinal regression models will estimate sex-specific trajectories and effects of risk and protective factors and secondary outcomes.

Ethics and dissemination The cohorts were approved by the ethics committees of the Statutory Physician Board of Rhineland-Palatinate (837.020.07; GHS), the University of Greifswald (BB 39/08; SHIP) and the Bavarian Chamber of Physicians (06068; KORA). Together with stakeholders in medical care and medical training, findings will be translated and disseminated into gender-sensitive health promotion and prevention.

\section{BACKGROUND}

Mental disorders have become a core challenge for healthcare in the 21st century. ${ }^{1}$ With a 1 year prevalence of over $30 \%$, mental disorders are highly prevalent and costly. Large cross-sectional population surveys have advanced our knowledge about different ways

\section{Strengths and limitations of this study}

- The multi-cohort consortium (GESA) implements GEnder-Sensitive Analyses of mental health trajectories and elaborates on their implications for prevention.

- Over 40000 participants from the German population contributed high-quality data on mental and somatic symptoms in multiple longitudinal cohorts.

- The combined samples originate from different German regions; their different socioeconomic characteristics will inform gender-sensitive analyses.

- Current waves lack strong gender measures; gender is instead estimated by socioeconomic proxies.

- The different measures, waves and age structures of the cohorts require substantial harmonisation and complicate interpretations.

in which common mental disorders affect and burden men and women ${ }^{1}$ (eg, quality of life, health behaviour, general health and gainful employment; for an overview see Kolip and Hurrelmann and Piccinelli and Wilkinson $^{2}{ }^{3}$ ): women are diagnosed more often with internalising disorders, especially depression, ${ }^{4}$ anxiety, somatoform ${ }^{1}$ and eating disorders. ${ }^{5}$ They differ from men regarding incidence, course and symptom profiles. Men are diagnosed more often with externalising disorders, substance (eg, alcoholism) and behavioural (eg, pathological gambling) addictions ${ }^{16}$ and conduct disorders. ${ }^{7}$

Differences between men and women are attributable to sex or gender differences. Sex as a biological construct is rooted in genetics, anatomy and physiology. ${ }^{8}$ Gender subsumes psychosocial variables that differentiate men and women. ${ }^{9}$ Sex and gender interact in the development of diseases. ${ }^{10}$ Yet, the distinction 
between sex and gender has been neglected in the health sciences, particularly in the area of mental health. ${ }^{8} 1112$ However, recommendations of public health agencies such as the US funding guidelines of the National Institutes of Health, ${ }^{13}$ the Canadian Institute of Gender and Health and the Robert Koch Institute in Germany have provided new impetus for sex-sensitive and gender-sensitive health research. ${ }^{14}$

The following constructs are pivotal to operationalise gender $^{815}$ :

1. Gender roles: Refer to behavioural norms within a society. They form by observing men and women in different social roles. Perceivers observe role congruent behaviours (eg, caregiving women in a family) and develop corresponding expectations (eg, women are caring). Gender roles evolved from an interaction of physical sex differences and culture; gender roles influence behaviour by biosocial processes (hormonal, self-regulation and social regulation). ${ }^{9}$

2. Gender identity: Reflects how individuals see themselves as relatively female or male (or across a continuum). It determines feelings and behaviours. ${ }^{8}$ Gender identity is measured on the two independent dimensions femininity/expressivity and masculinity/ instrumentality. ${ }^{16-18}$

3. Gender relations: Describe how individuals interact with or are treated by others based on their ascribed or displayed gender.

4. Institutionalised gender: Refers to the distribution of power between women, men and others in the institutions of a society (ie, social, political, educational etc). It shapes social norms defining and maintaining different expectations and opportunities for men and women. $^{8}$

To overcome shortcomings in existing data recent research has developed gender measures that allow assessing gender in population-based studies that did not originally include measures of gender. ${ }^{11}{ }^{19}$ Pelletier and colleagues ${ }^{11}$ have advocated to assess gender-related individual differences by characteristics that discriminate men and women. After conducting principal component factor analysis and logistic regression analysis (with sex as criterion) in a sample of patients with acute coronary syndrome (ACS), they identified seven variables associated with sex: primary earner status, personal income, weekly hours of housework, primary responsibility for housework, level of stress at home, masculinity scores, and femininity scores. Interestingly, a feminine gender score but not female sex was associated with traditional risk factors for ACS. A similar score was proposed by Smith and Koehoorn ${ }^{19}$ that was based on work, childcaring and education. Both seem to measure a combination of gender roles and institutionalised gender.

The German Federal Ministry of Education and Research (BMBF) called for 'gender-sensitive studies in preventive and public health research' as part of the funding initiative life-long health, to promote the health of women and men. This paper presents the rationale and methodological approach of the project 'GEnder-Sensitive Analyses of mental health trajectories and implications for prevention: A multi-cohort consortium (GESA'.

\section{Study aims}

GESA performs gender-sensitive analyses combining three large-scale, prospective, representative cohorts with highquality health data in order to fill the gaps of gender-related knowledge in mental health. ${ }^{8} 12$ Each cohort includes multiple samples with two to four follow-ups. GESA seeks to (1) advance knowledge about vulnerable phases for the development of common mental disorders applying a developmental (lifespan) approach, ${ }^{20}{ }^{21}$ which will be complemented by gender-sensitive analyses. Here, we aim to identify gender-specific symptom patterns, which will allow to refine gender-sensitive assessment methods. (2) Following the vulnerability-stress model of mental disorders, pathogenic (risk factors and behaviours) and salutogenic factors (personal, biological and social protective factors) will be identified by comprehensive and large-scale assessments. We differentiate stable and variable protective (salutogenic) and stable and variable risk factors (pathogenic). Stable factors include personality, socioeconomic factors, physical environment (noise annoyance), ${ }^{22}$ urbanity, reported adverse childhood experiences, ${ }^{23}$ migration background ${ }^{24}$ and the presence of chronic medical conditions. Variable factors, which are more accessible to preventive efforts, include social support, ${ }^{25}$ loneliness, ${ }^{26} 27$ perceived and work-related stress, ${ }^{28}$ health behaviour (smoking, alcohol, physical activity) and healthcare utilisation. The relationship of baseline to follow-up conditions is further modified by intervening critical life events (including somatic diseases) or life cycle demands (eg, marriage, childbirth, or retirement). By exploring socioeconomic influences, we account for the diversity within groups of men and women and avoid creating an artificially homogeneous picture. (3) We will determine the effects of mental health on major outcome variables especially subjective health, healthcare behaviour and utilisation and quality of life. Women have higher rates of sick leaves ${ }^{29}$ in addition to longer-lasting disabilities ${ }^{1}$ and report a lower subjective quality of life. ${ }^{30}$ We will relate the findings to local and regional, socioeconomic, environmental and healthcare conditions. Figure 1 gives an overview over the suggested relations and all measured variables with a special emphasis on differentiating between stable and variable risk and protective factors. Health promotion and prevention will be advanced by the increase of knowledge on sex and gender as determinants of mental health, health behaviour and mental health outcomes, while accounting for social, economic or environmental living conditions.

\section{METHODS AND ANALYSIS}

\section{Study setting and participants}

The overall project consists of three major, ongoing, longitudinal cohorts in middle, southern and northeast Germany: The Gutenberg Health Study (GHS), the Cooperative Health Research in the Augsburg Region 


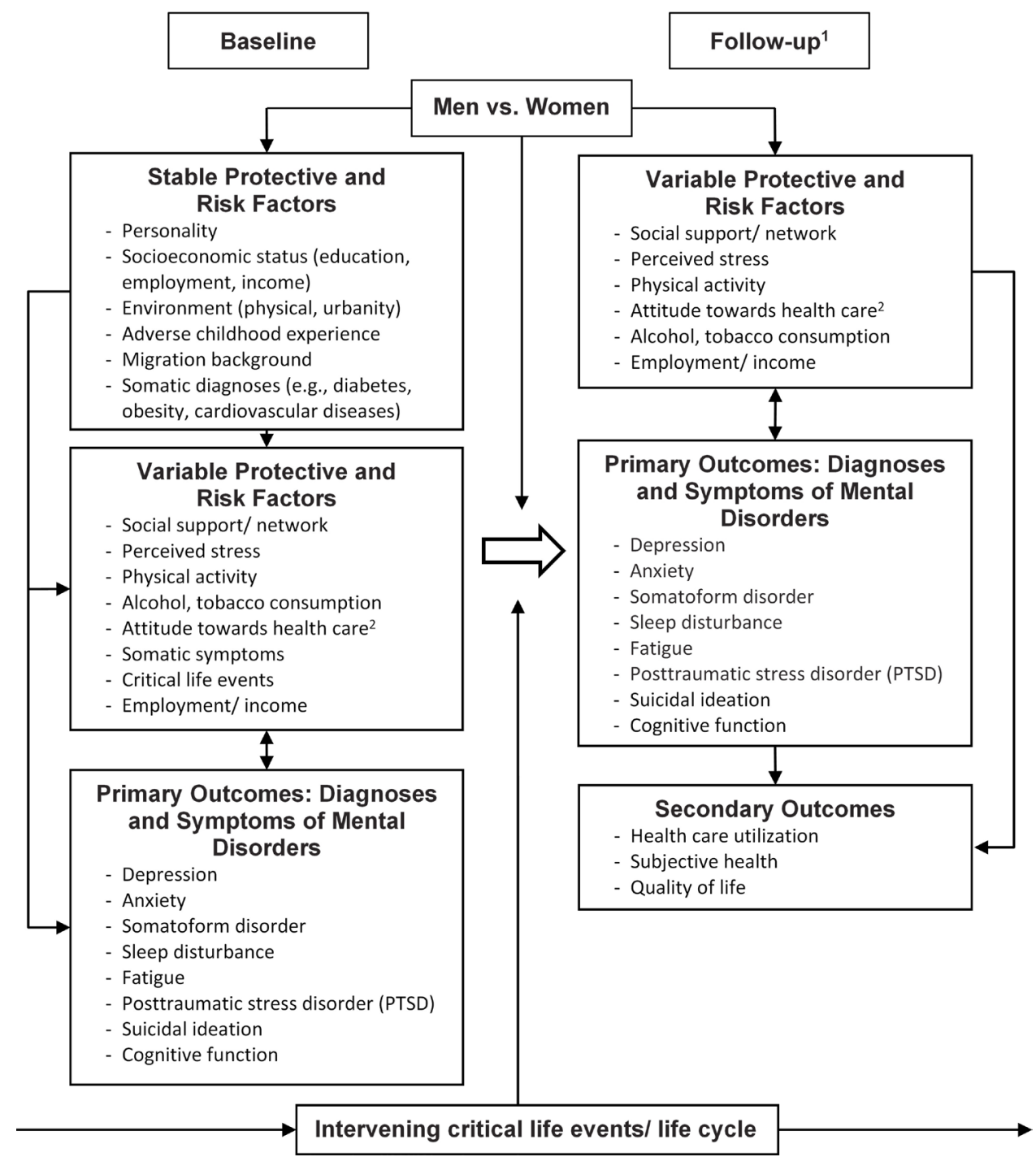

Figure 1 Relationships between common mental disorders, risk and protective factors and outcomes. ${ }^{1}$ All studies are ongoing; up to three follow-ups conducted to date. ${ }^{2}$ Only in SHIP.

(KORA) and the Study of Health in Pomerania (SHIP). Table 1 gives an overview over the specifics of the cohorts.

All cohorts are being recruited following comparable protocols based on stratified random selection of participants from the local registries. Registration is mandatory for any individual residing in Germany. Thus, representative samples of the general population are available based on comparative, stratified sampling (by sex, age and urban-rural residence) in different regions of Germany with comparable recruitment efficiency (GHS: 60\%; KORA: 70\%-80\%; SHIP: 44\%-69\%). All studies contacted non-responders to estimate their effects on results. The longitudinal cohorts aimed at investigating the complex associations between risk factors, subclinical and clinical diseases; consecutive follow-ups were conducted in intervals of 2.5 years, respectively 5 (and up to 7 years). Each was powered for predicting the combined endpoint of primary myocardial infarction or cardiac death. All cohorts covered extensive anthropometric measurements, biobanking, laboratory and medical technical examinations (eg, spiroergometry, vascular function). ${ }^{31-33}$ Data were acquired via thorough medical and psychological examinations (GHS 4-6 hours; KORA 3 hours; SHIP/SHIP-TREND up to 25 hours) in the cohort centres and additional telephone interviews. We focus on the extensive and overlapping sets of standardised and validated measures (self-report, interview, medical history and diagnoses) of mental health domains and related symptoms, as well as indices of distress, health behaviour, healthcare utilisation and subjective health.

Figure 2 illustrates the different samples of the cohorts and assessment years. The GHS recruited in the city of Mainz and the county of Mainz-Bingen in Midwest Germany since 2007. It started out with the largest sample with two completed follow-ups after 2.5 and 5 years (7.5 years and 10 years ongoing). ${ }^{33}$

The data were derived from three independent crosssectional population-based WHO monitoring trends and determinants on cardiovascular diseases (MONICA) surveys conducted in the region of Augsburg (southern 
Table 1 Overview of the participating cohorts

\begin{tabular}{|c|c|c|c|c|}
\hline & GHS & MONICA/KORA & SHIP & $\begin{array}{l}\text { Combined } \\
\text { samples }\end{array}$ \\
\hline $\begin{array}{l}\text { Sampling area in } \\
\text { Germany }\end{array}$ & $\begin{array}{l}\text { City of Mainz and County of } \\
\text { Mainz-Bingen, Midwest }\end{array}$ & $\begin{array}{l}\text { City and county of Augsburg, } \\
\text { south }\end{array}$ & $\begin{array}{l}\text { Western Pomerania, north- } \\
\text { east }\end{array}$ & \\
\hline Age at baseline & $35-74$ & $25-74$ & 20-79 & $20-79$ \\
\hline Inclusion criteria & Residency in the study area. & $\begin{array}{l}\text { Residency in the study area. } \\
\text { German nationality. }\end{array}$ & $\begin{array}{l}\text { Residency in the study } \\
\text { area. } \\
\text { German nationality. }\end{array}$ & \\
\hline Stratification & \multicolumn{4}{|c|}{ Age, sex and city/county of residence } \\
\hline Participation rate & $53 \%$ & $70 \%-80 \%$ & $\begin{array}{l}69 \% \text { SHIP } \\
55 \% \text { TREND }\end{array}$ & $53 \%-80 \%$ \\
\hline $\begin{array}{l}\text { Years baseline } \\
\text { examinations }\end{array}$ & S1 2007-2012 & $\begin{array}{l}\text { S1 } 1984-1985 \\
\text { S2 1989-1990 } \\
\text { S3 1994-1995 } \\
\text { S4 1999-2001 }\end{array}$ & $\begin{array}{l}\text { SHIP } 1997-2001 \\
\text { SHIP-Trend 2008-2012 }\end{array}$ & $\begin{array}{l}\text { Starting } 1984 \\
\text { ongoing }\end{array}$ \\
\hline Number of follow-ups & 4 & $2-3$ & 4 & 4 \\
\hline Follow-up intervals & $21 \frac{1}{2}$ (CATI), 5 years & $5-7$ years & After 5 years & $2.5-7$ years \\
\hline Non-responder & $\begin{array}{l}\text { Structured questionnaires } \\
\text { for non-responders including } \\
\text { cardiovascular risk factor } \\
\text { profile, concomitant diseases, } \\
\text { sociodemography. }\end{array}$ & Depending on sample. & $\begin{array}{l}\text { Information about non- } \\
\text { responders includes age, } \\
\text { gender and the reason for } \\
\text { not taking part. }\end{array}$ & \\
\hline
\end{tabular}

CATI, computer-assisted telephone interview; GHS, Gutenberg Health Study; KORA, Cooperative Health Research in the Augsburg Region; MONICA, monitoring trends and determinants on cardiovascular diseases; SHIP, Study of Health in Pomerania.

Germany) with 13427 men and women (response rate $77 \%$ ) aged 25-74 years in 1984/1985 (S1), 1989/1990 (S2) and 1994/1995 (S3). Each sample was reassessed up to four times and thus assuring a prospective follow-up within the framework of the KORA ${ }^{31}$

SHIP started following the German reunification, in 1996 in the east of Western Pomerania, northeast Germany. It includes two samples (SHIP and SHIP-TREND) with a maximum of four follow-ups. In addition to regular follow-ups, all participants from the baseline sample (SHIP) were invited to participate in SHIP-Life Events and Gene-Environment Interaction in Depression(SHIPLEGEND).$^{32}$ SHIP-LEGEND comprised comprehensive psychological assessments. A total of 2400 subjects participated.

\section{Outcomes}

As figure 1 shows, the primary outcomes refer to common mental disorders such as depression, anxiety, somatoform disorders; symptoms such as fatigue, sleep disturbances, suicidal ideation; and cognitive functions. A plethora of validated and established measures was used to span the 
GHS

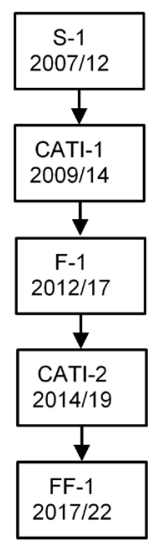

MONICA/KORA ${ }^{1}$

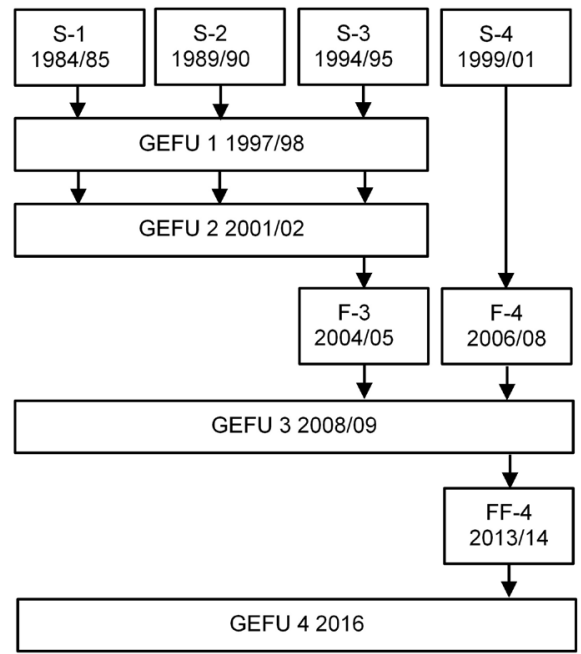

SHIP

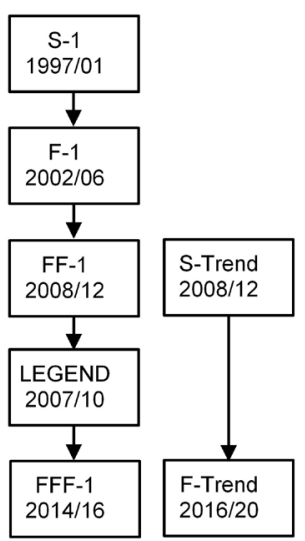

Figure 2 . Overview of cohort samples and assessment years. CATI, computer-assisted telephone interview; F, follow-up; FF, follow-up of the follow-up; FFF, follow-up of the follow-up of the follow-up, GEFU, postal general health follow-up; GHS, Gutenberg Health Study; KORA, Cooperative Health Research in the Augsburg Region; MONICA, monitoring trends and determinants on cardiovascular diseases; S, sample; SHIP, Study of Health in Pomerania. ${ }^{1}$ Additionally, numerous smaller-scale examinations and surveys on special issues have taken place also older participants were examined within KORA age (includes participants $\geq 65$ years from S1 to S4).

whole range of mental health-related symptoms. Except for cognitive functions all variables were assessed with self-report questionnaires that participants filled out on their own except for the computer-assisted telephone interviews (CATIs) assessments by the GHS. Additionally, SHIP-LEGEND assessed mental disorders in personal interviews using the Munich-Composite International Diagnostic Interview (M-CIDI) ${ }^{35}$ by trained psychology students, ${ }^{34}$ which diagnoses mental disorders according to the definitions of the Diagnostic Criteria for Research of ICD-10 and DSM-III-R. Secondary outcomes refer to healthcare behaviour and utilisation, subjective health status, quality of life and well-being. Again, measurements were taken as self-report or telephone interview. Table 2 gives an overview of the harmonised measures available in multiple cohorts. These shared measures will be complemented by measures available in single cohorts. The outcomes will be used for primary and secondary outcomes as depicted in figure 1.

While measures of sex are readily available in all cohorts, specific gender measures had not been previously implemented in them. To overcome this, we will create and validate a gender index similar to Smith and Koehoorn ${ }^{19}$ and Pelletier and colleagues. ${ }^{11}$ In the course of the harmonisation process, it became clear that the cohorts do not support using identical indexes. The GHS will derive a gender index by factor analysis from theoretically identified variables; especially, demographic variables (eg, education, contribution to household income) and indicators of quality and quantity of social relations to estimate the conformity with traditional feminine or masculine gender roles. Similar gender indexes will be established in each cohort. To cross-validate the indexes findings will be compared between cohorts.

To complement this gender index, which mainly measures gender roles and possibly institutionalised gender, ${ }^{19}$ the new GHS wave (FF-1) added established measures of gender roles and identity. The German version of the Personal Attributes Questionnaire ${ }^{20}$ was used to determine the sex-typing of personality. This selfreport instrument consists of the two independent dimensions, 'expressivity' and 'instrumentality', corresponding to stereotypically feminine, respectively masculine traits. Earlier research has shown that people high on both scales show more positive health outcomes. ${ }^{16} 36$ The German version of the Gender Role Orientation scale ${ }^{3738}$ was used to assess traditional normative expectations regarding men and women. Conformity to traditional masculine gender roles has been associated with negative mental health outcomes in men. ${ }^{39}$

\section{Statistical analysis plan}

We will perform secondary analyses on the three cohorts. Data will be analysed separately and jointly using aggregate statistics for evidence synthesis. Separate analyses will allow cross-validating findings from one cohort within the other, and we will test whether results generalise across samples and measures. Figure 3 gives an overview of the analytic procedures of GESA.

The data combination will rely on the DataSHIELD software infrastructure, which enables analyses that comply with data protection regulations by only sharing anonymous, aggregated data, while the individual data remain in the respective sites. ${ }^{40} 41$ The data combination 
Table 2 Harmonised variables per cohort

\section{Constructed variables}

Harmonisation process

Available for GHS, KORA and SHIP

Depression

PHQ-9 scales or combination of PHQ-9 and BDI-2 recoded into binary variable

Suicidal ideation Items from PHQ-9 and BDI-2, recoded into binary variable

Sleep problems

Smoking status Question about falling asleep and PHQ-9 sleep item recoded into binary variable

BMI Derived from several smoking variables including current and past habits, recoded into categories (regular/ irregular/ ex-smoker/ never smoked)

BMl weight/height ${ }^{2}$, continuous variable

Physical activity

Diabetes

Derived from variables of activities and doing sports, recoded into binary variable

Myocardial infarction Self-reported (diagnosed by doctor) and metabolic factors recoded into binary variable

Stroke

Cancer Self-reported (diagnosed by doctor), recoded into binary variable

Chronic disease Self-reported (diagnosed by doctor), recoded into binary variable Self-reported, recoded into binary variable

Sex

Any presence of diabetes, myocardial infarction, stroke and cancer, recoded into binary variable

Self-reported (male/ female)

Education (in years)

Marital status

Self-reported or derived from birthday and study date

Self-reported or derived from educational degree and work educational degree

People per household

Living with partner

Recoded into categories married, not married/single, divorced, widowed Self-reported participant and spouse, children etc., continuous variable

Similar questions in cohorts (yes/no)

Living alone Derived from people per household (yes/ no)

Current employment

Derived from combination of employment variables, recoded into categories: no, fulltime, part-time, marginally employed

Household income

Ordinal variables with different categories per cohort, new metric variable constructed with mean value of income category per person

Available for KORA and SHIP

Anxiety

Combination of GAD-7 and four CID items, recoded into binary variable (GAD-7 $\geq 9$ as anxiety, any CID-S item score as anxiety)

PTSD

ICD-10 with four criteria: (A) traumatic event, (B) intrusion, (C) avoidance and (D) hyperarousal; fulfilment of A, B, C or D is coded as full PTSD, fulfilment of A and B, C or $D$ is coded as partial PTSD, no fulfilment of $A$ is coded as no PTSD

\begin{tabular}{|c|c|}
\hline Alcohol consumption & $\begin{array}{l}\text { Based on amounts and frequency of alcohol consumption, recoded into ordinal variable } \\
\text { (categories: no, low, high) }\end{array}$ \\
\hline Emotional abuse childhood & $\begin{array}{l}\text { Combination of CTS item and CTQ item, similar answer categories, recoded into ordinal } \\
\text { variable (five categories: not at all to very often) }\end{array}$ \\
\hline $\begin{array}{l}\text { Emotional neglect childhood } \\
\text { Sexual abuse childhood } \\
\text { Physical abuse childhood } \\
\text { Physical neglect childhood }\end{array}$ & $\begin{array}{l}\text { Combination of CTS and CTQ item, similar answer categories, recoded into one ordinal } \\
\text { variable (five categories: not at all to very often) }\end{array}$ \\
\hline Type 2 diabetes & $\begin{array}{l}\text { Self-reported diabetes (diagnosed by doctor), metabolic factors and self-reported type of } \\
\text { diabetes, recoded into ordinal variable (categories: no, yes, other type) }\end{array}$ \\
\hline Parents with diabetes & $\begin{array}{l}\text { Diabetes for mother and father each or combined, recoded into ordinal variable (no, } \\
\text { father, mother, both) }\end{array}$ \\
\hline History of myocardial infarction & Self-reported (diagnosed by doctor), recoded into binary variable \\
\hline Hypertension & $\begin{array}{l}\text { Blood pressure measures with same measurement units, recoded into continuous } \\
\text { variable }\end{array}$ \\
\hline Total cholesterol & $\begin{array}{l}\text { Cholesterol measurement with different measurement units, recode measurement units } \\
\text { and recoded into continuous variable }\end{array}$ \\
\hline
\end{tabular}


Table 2 Continued

\begin{tabular}{ll}
\hline Constructed variables & Harmonisation process \\
\hline HDL-cholesterol & $\begin{array}{l}\text { HDL-cholesterol measurement with different measurement units, recoded into continuous } \\
\text { variable }\end{array}$ \\
\hline Height (in cm) & Measured \\
Waist circumference (in cm) & Measured \\
\hline Hip circumference (in cm) & Measured \\
Waist-height ratio & Waist circumference/height \\
\hline Reason for retirement & Recoding categories and recoded into ordinal variable with three categories \\
\hline $\begin{array}{l}\text { Duration of unemployed (years and } \\
\text { months) }\end{array}$ & $\begin{array}{l}\text { Exact number or calculated from unemployment since certain date, recoded into } \\
\text { continuous variable }\end{array}$ \\
Available for GHS and SHIP & Self-reported (yes/ no) \\
Pregnancy & Recoded into binary variable \\
Lifetime unemployment & $\begin{array}{l}\text { Derived from having children and number of children, recoded into one continuous } \\
\text { variable and one binary variable }\end{array}$ \\
\hline Children &
\end{tabular}

BDI, beck depression inventory; BMI, body mass index; CID-S, composite international diagnostic screener; CTQ, Child Trauma Questionnaire; CTS, Childhood Trauma Screener; GAD, generalized anxiety disorder; GHS, Gutenberg Health Study; HDL, high-density lipoprotein; KORA, Cooperative Health Research in the Augsburg Region; PHQ-9, Patient Health Questionnaire; PTSD, post-traumatic stress disorder; SHIP, Study of Health in Pomerania.

use multivariate meta-analytic techniques ${ }^{42}$ for data aggregation (eg, using covariance matrices). These techniques allow data combination without information loss (eg, regarding relative sample size) and are consistent with individual level analyses.

In a first step, univariate meta-analysis of regression estimates will be conducted. This will detect heterogeneity of effects (eg, assessed by $\mathrm{I}^{2}$ ) between datasets as part of the meta-analytic approach. To limit heterogeneity, we will explore dataset exclusion and individual-level analyses to identify sources of heterogeneity. Remaining heterogeneity will be modelled using random effects. Differences in the availability of measurements between the cohorts in the course of time require extensive harmonisation prior to data combination. Thus, longitudinal regression models (that do not prescribe a fixed grid of times), with gender $\times$ time interactions, will be estimated at the three study centres

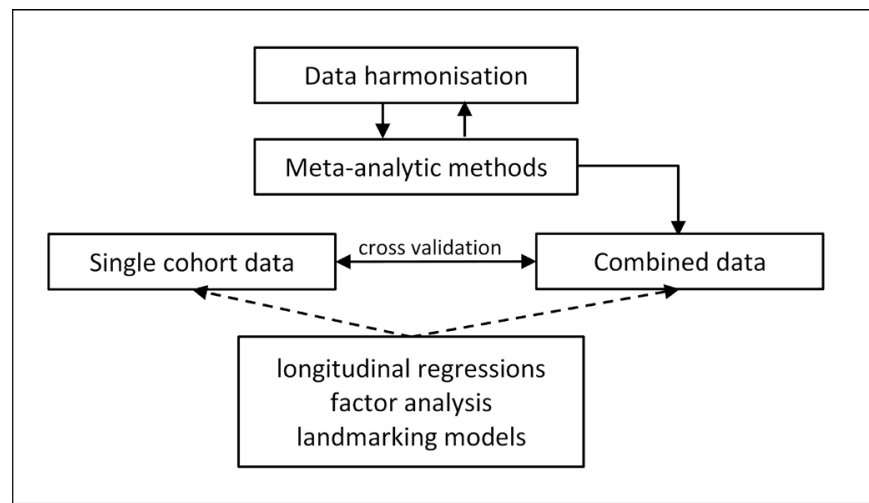

Figure 3 Overview of analysis plan GESA. GESA, GEnderSensitive Analyses of mental health trajectories and implications for prevention. as a basis for combination. Both analyses can uncover differences between different study and age cohorts. Further, the longitudinal regressions will yield joint sex-specific trajectories that describe the time course of common mental disorders (aim 1). We will also consider non-linear (ie, quadratic or exponential) terms, for example, for modelling mental disorder peaks in middle adulthood. These trends will be analysed for men and women potentially uncovering differences in peaks. Aggregate analyses of the sizeable cohorts enable us to perform differentiated analyses of subgroups (eg, minority populations such as migrants) within men and women.

There is a considerable overlap regarding crucial concepts such as depression, which were assessed using both identical and different measures. For instance, each cohort included the Patient Health Questionnaire $(\text { PHQ-9 })^{43}$ as a measure of depression in at least two assessments. Additionally, the Depressed Mood/ Exhaustion scale, ${ }^{44}$ the Geriatric Depression Scale (GDS-15), ${ }^{45}$ the Hospital Anxiety and Depression Scale, ${ }^{46}$ the CIDI $^{35}$ and the Composite International Diagnostic-Screener ${ }^{47}$ were used. Data from multiple measures of the same concept will be converted into a common metric using Item Response Theory. ${ }^{48}$ We plan to generate a gendersensitive metric by separate analyses for male and female participants accounting for demographic and socioeconomic background.

The secondary objective (risks and protective factors; consequences of mental disorders) will also be addressed by longitudinal regression models, considering mental disorders, healthcare utilisation, quality of life and subjective health as outcomes (see table 2). Research teams will propose specific analyses to the steering committee for 
approval. The analyses will test the effects of sex $\times$ time interactions with and without a gender index for the different outcomes. Different measurement times will be addressed by landmarking approaches, which can incorporate risk factors that have occurred up to a certain landmark lifetime. ${ }^{49}$ Results from landmarking models, fitted at each centre, will be combined by multivariate metaanalysis. For factors that are absent for one of the cohorts, imputation approaches (based on relations obtained from the other cohorts) will be considered.

\section{Data collection, management and oversight}

Each cohort puts strong emphasises on data quality by frequently training interviewers, physicians and any personal interacting with participants. To complement training all current interviews are computer-assisted. All cohorts can build on a long history of research and field work. The implementation of standard operating procedures and the employment of qualified personnel lead to a high level of quality and efficiency in the realisation of studies. Data are managed at the single cohort centres following well established standards. Data aggregation is supervised by Prof Dr Binder at the University of Freiburg.

\section{PATIENT AND PUBLIC INVOLVEMENT}

The BMBF's call determined the overarching goal to conduct gender-sensitive analyses to improve disease prevention and promote lifelong health. The investigators, who are in continuous contact with key stakeholders, especially, German sickness funds, the German statutory pension insurance and patient advocacy groups, continue to specify the research questions.

\section{Ethics and dissemination}

\section{Dissemination policy}

Yearly in-person meetings supplement monthly telephone conferences between principle investigators and other researchers. The yearly meetings are supported by the scientific advisory board (Eric Brunner, Alexandra KautzkyWiller, Eva Prescott and Monika Sieverding). Due to the duration of the data harmonisation process, mayor healthcare organisations and other stakeholders (eg, sickness funds, patient advocacy groups) are planned to join the in-person meetings in the last period of the project. The investigators will develop further strategies for dissemination, which will be adjusted to the regional demands. They will be coordinated and approved by the advisory board.

\section{DISCUSSION}

Population-based designs with register-based sampling of participants offer the highest external validity. The longitudinal data will provide evidence on the temporal course and potential causal relations between gender, risk and protective factors and mental disorders. A strength of the combined samples is that they originate from different German regions, with different socioeconomic or regional characteristics, such as economic parameters: Unemployment rates are highest, discretionary incomes, and life expectancy lowest in Greifswald (SHIP). Mainz (GHS) and Augsburg (KORA) are economically stronger regions with Mainz (GHS) showing slightly higher discretionary incomes. These regional differences allow us to compare effects of relative and absolute deprivation. For historical reasons the study regions show pronounced differences regarding full-time employment rates among mothers resulting in different gender pay gaps. ${ }^{50}$ Further, life expectancy is highest in Mainz (GHS), while Greifswald (SHIP) shows the lowest life expectancy and the biggest gender gap. ${ }^{51}$ Combining the three studies will allow a more complete representation of the German population (eg, former eastern and western regions) and a bigger set of measures, even though the data harmonisation process poses a considerable challenge. Separate analyses will allow cross-validation. The application of novel analytical methods (ie, network analyses across lifespan) may become a blueprint for other multi-cohort studies. The purpose of our cohort is to fill the gaps of gendersensitive knowledge of mental health and to provide the basis for scientifically grounded strategies of gendersensitive health promotion and prevention.

\section{Author affiliations}

${ }^{1}$ Department of Psychosomatic Medicine and Psychotherapy, University Medical Center of the Johannes Gutenberg University Mainz, Mainz, Germany

${ }^{2}$ Institute of Medical Biometry and Statistics, Faculty of Medicine and Medical Center, University of Freiburg, Freiburg im Breisgau, Germany

${ }^{3}$ Department of Psychiatry and Psychotherapy, University Medicine Greifswald, Greifswald, Germany

${ }^{4}$ Department of Psychosomatic Medicine and Psychotherapy, University Medical Center Giessen and Marburg, Giessen, Germany

${ }^{5}$ Institute of Epidemiology, Helmholtz-Zentrum München, German Research Center for Environmental Health, Neuherberg, Germany

${ }^{6}$ Department of Psychosomatic Medicine and Psychotherapy, Klinikum rechts der Isar, Technische Universität München (TUM), München, Germany

${ }^{7}$ Department of Psychiatry, Medical Faculty, Leipzig University, Leipzig, Germany ${ }^{8}$ Preventive Cardiology and Preventive Medicine - Center for Cardiology, University Medical Center of the Johannes Gutenberg University Mainz, Mainz, Germany

${ }^{9}$ Center for Thrombosis and Hemostasis (CTH), University Medical Center of the Johannes Gutenberg University Mainz, Mainz, Germany

${ }^{10}$ DZHK (German Center for Cardiovascular Research), partner site RhineMain, Mainz, Germany

Acknowledgements The authors are grateful to all study participants. Further, the authors thank the staff involved in the planning, organisation and conduct of the GHS, KORA and SHIP.

Contributors All authors contributed to the development and refinement of the GESA consort. MB, EB, JB, HB, HG, JK, KL, GS and PW are grant holders. JB and MB drafted the first version of the GESA grant proposal, which was thoroughly revised by all authors. Based on this proposal JB, AT and MB drafted the first version of the study protocol, which was substantially revised by $\mathrm{D} 0$ and subsequently refined and approved by all authors.

Funding GESA is funded by the Federal Ministry of Education and Research (BMBF; Nr. 01GL1718A).

Disclaimer The BMBF had no role in the design of this study and will not have any role during its execution, analyses, interpretation of the data, or decision to submit results.

Competing interests HJG has received travel grants and speakers honoraria from Fresenius Medical Care, Neuraxpharm and Janssen Cilag. HJG has received research funding from the German Research Foundation (DFG), the German Ministry 
of Education and Research (BMBF), the DAMP Foundation, Fresenius Medical Care, the EU "Joint Programme Neurodegenerative Disorders (JPND) and the European Social Fund (ESF)".

\section{Patient consent for publication Not required.}

Ethics approval The cohorts were approved by the ethics committees of the Statutory Physician Board of Rhineland-Palatinate (GHS: 837.020.07; original vote: 22.3.2007, latest update: 20.10), the University of Greifswald (SHIP: BB 39/08; original vote: 19.6.2008) and the Bavarian Chamber of Physicians (Bayerische Landesärztekammer; KORA: 06068). All participants have given written consent and have the right to withdraw their consent at any time. Local data protection officers supervise and monitor protection of participants' data.

\section{Provenance and peer review Not commissioned; externally peer reviewed.}

Open access This is an open access article distributed in accordance with the Creative Commons Attribution Non Commercial (CC BY-NC 4.0) license, which permits others to distribute, remix, adapt, build upon this work non-commercially, and license their derivative works on different terms, provided the original work is properly cited, appropriate credit is given, any changes made indicated, and the use is non-commercial. See: http://creativecommons.org/licenses/by-nc/4.0/.

\section{ORCID iDs}

Juliane Burghardt http://orcid.org/0000-0003-0690-0731

Karl Heinz Ladwig http://orcid.org/0000-0003-0710-1720

\section{REFERENCES}

1 Wittchen HU, Jacobi F, Rehm J, et al. The size and burden of mental disorders and other disorders of the brain in Europe 2010. Eur Neuropsychopharmacol 2011;21:655-79.

2 Kolip P, Hurrelmann K. Handbuch Geschlecht und Gesundheit: Männer und Frauen Im Vergleich. Bern: Hogrefe Verlag, 2016.

3 Piccinelli M, Wilkinson G. Gender differences in depression. critical review. Br J Psychiatry 2000;177:486-92.

4 Kuehner $\mathrm{C}$. Why is depression more common among women than among men? Lancet Psychiatry 2017;4:146-58.

5 Duncan AE, Ziobrowski HN, Nicol G. The prevalence of past 12-month and lifetime DSM-IV eating disorders by BMI category in US men and women. European Eating Disorders Review 2017;25:165-71.

6 Jacobi F, Wittchen HU, Holting C, et al. Prevalence, co-morbidity and correlates of mental disorders in the general population: results from the German health interview and examination survey (GHS). Psychol Med 2004;34:597-611.

7 LaPlante DA, Nelson SE, LaBrie RA, et al. Men \& women playing games: gender and the gambling preferences of lowa gambling treatment program participants. J Gamb/ Stud 2006;22:65-80.

8 Tannenbaum C, Greaves L, Graham ID. Why sex and gender matter in implementation research. BMC Med Res Methodol 2016;16:145.

9 Eagly $\mathrm{AH}$, Wood W. Social role theory of sex differences. In: The Wiley Blackwell encyclopedia of gender and sexuality studies. John Wiley \& Sons, Ltd, 2016.

10 Regitz-Zagrosek V, Oertelt-Prigione S, Prescott E, et al. Gender in cardiovascular diseases: impact on clinical manifestations, management, and outcomes. Eur Heart J 2016;37:24-34.

11 Pelletier R, Ditto B, Pilote L. A composite measure of gender and its association with risk factors in patients with premature acute coronary syndrome. Psychosom Med 2015;77:517-26.

12 Starker A, Rommel A, Saß A-C. [Men's health report - Conclusion and challenges for sex- and gender-sensitive health reporting]. Bundesgesundheitsblatt Gesundheitsforschung Gesundheitsschutz 2016;59:979-85.

13 National Institutes of Health. Consideration of sex as a biological variable in NIH-funded research NOT-OD-15-102, 2015.

14 Jahn I, Foraita R. [Gender-sensitive epidemiological data analysis: methodological aspects and empirical outcomes. Illustrated by a health reporting example]. Bundesgesundheitsblatt, Gesundheitsforschung, Gesundheitsschutz 2008:51:13-27.

15 Johnson JL, Greaves L, Repta R. Better science with sex and gender: facilitating the use of a sex and gender-based analysis in health research. Int J Equity Health 2009;8:14.

16 Bem SL. On the utility of alternative procedures for assessing psychological androgyny. J Consult Clin Psychol 1977;45:196-205.

17 Goldschmidt S, Linde K, Alfermann D, et al. Das

Geschlechtsrollenselbstkonzept von Erwachsenen. Eine Überprüfung Der deutschsprachigen version des personal attributes questionnaire (PAQ). Psychosozial 2014.
18 Spence JT, Helmreich R, Stapp J. The personal attributes questionnaire: a measure of sex role stereotypes and masculinityfemininity. Washington: Journal Supplement Abstract Service, American Psychological Association, 1978.

19 Smith PM, Koehoorn M. Measuring gender when you don't have a gender measure: constructing a gender index using survey data. Int $J$ Equity Health 2016;15:82.

20 Erikson E, Erikson JM. The life cycle completed. New York: Norton, 1982.

21 Havighurst R. Developmental tasks and education. New York: David McKay, 1992

22 Beutel ME, Jünger C, Klein EM, et al. Noise annoyance is associated with depression and anxiety in the general Population- the contribution of aircraft noise. PLoS One 2016;11:e0155357.

23 Beutel ME, Tibubos AN, Klein EM, et al. Childhood adversities and distress - The role of resilience in a representative sample. PLoS One 2017;12:e0173826.

24 Beutel ME, Jünger C, Klein EM, et al. Depression, anxiety and suicidal ideation among 1 st and 2 nd generation migrants - results from the Gutenberg health study. BMC Psychiatry 2016;16:288.

25 Beutel ME, Brähler E, Wiltink J, et al. Emotional and tangible social support in a German population-based sample: development and validation of the brief social support scale (BS6). PLoS One 2017;12:e0186516

26 Zebhauser A, Baumert J, Emeny RT, et al. What prevents old people living alone from feeling Lonely? findings from the KORA-Age-study. Aging Ment Health 2015;19:773-80.

27 Zebhauser A, Hofmann-Xu L, Baumert J, et al. How much does it hurt to be Lonely? mental and physical differences between older men and women in the KORA-Age study. Int $J$ Geriatr Psychiatry 2014;29:245-52.

28 Rose DM, Seidler A, Nübling M, et al. Associations of fatigue to work-related stress, mental and physical health in an employed community sample. BMC Psychiatry 2017;17:167.

29 Marschall J, Hildebrandt-Heene S, Nolting H-D, et al. Gesundheitsreport 2016: analyse Der Arbeitsunfähigkeitsdaten Schwerpunkt: Gender und Gesundheit. medhochzwei Verlag, 2016: 175 .

30 Dreger S, Gerlinger T, Bolte G. Gender inequalities in mental wellbeing in 26 European countries: do welfare regimes matter? Eur $J$ Public Health 2016:26:872-6.

31 Holle R, Happich M, Löwel H, et al. KORA - A Research Platform for Population Based Health Research. Das Gesundheitswesen 2005;67:19-25.

32 Volzke H, Alte D, Schmidt CO, et al. Cohort profile: the study of health in Pomerania. Int J Epidemiol 2011;40:294-307.

33 Wild PS, Zeller T, Beutel M, et al. [The Gutenberg Health Study]. Bundesgesundheitsblatt Gesundheitsforschung Gesundheitsschutz 2012:55:824-9.

34 Grabe HJ, Schwahn C, Mahler J, et al. Moderation of adult depression by the serotonin transporter promoter variant (5-HTTLPR), childhood abuse and adult traumatic events in a genera population sample. Am J Med Genet B Neuropsychiatr Genet 2012;159B:298-309.

35 Wittchen $\mathrm{H}-\mathrm{U}$, Lachner G, Wunderlich $\mathrm{U}$, et al. Test-Retest reliability of the computerized DSM-IV version of the Munich-Composite international diagnostic interview (M-CIDI). Soc Psychiatry Psychiatr Epidemiol 1998;33:568-78.

36 Sieverding M. Geschlecht und Gesundheit. In Hogrefe, 2005: 55-70.

37 Brogan D, Kutner NG. Measuring sex-role orientation: a normative approach. J Marriage Fam 1976;38:31-9.

38 Krampen G. Eine Kurzform Der Skala Zur Messung normativer Geschlechtsrollenorientierungen. Zeitschrift Fur Soziologie 1983;12:152-6.

39 Wong YJ, Ho M-HR, Wang S-Y, et al. Meta-Analyses of the relationship between conformity to masculine norms and mental health-related outcomes. J Couns Psychol 2017;64:80-93.

40 Jones EM, Sheehan NA, Masca N, et al. DataSHIELD - shared individual-level analysis without sharing the data: a biostatistical perspective. Nor Epidemiol 2012;21.

41 Gaye A, Marcon Y, Isaeva J, et al. DataSHIELD: taking the analysis to the data, not the data to the analysis. Int J Epidemiol 2014;43:1929-44.

42 Jackson D, Riley R, White IR. Multivariate meta-analysis: potential and promise. Stat Med 2011;30:2481-98.

43 Kroenke K, Spitzer RL, Williams JB. The Phq-9. J Gen Intern Med 2001;16:606-13

44 Ladwig K, Marten-Mittag B, Baumert J. Case-Finding for depressive and exhausted mood in the general population: reliability and validity of a symptom-driven diagnostic scale. results from the prospective MONICA/KORA Augsburg study. Ann Epidemiol 2004;14:332-8. 
45 Yesavage JA, Sheikh JI. 9/Geriatric depression scale (GDS). Clin Gerontol 1986;5:165-73.

46 Bjelland I, Dahl AA, Haug TT, et al. The validity of the hospital anxiety and depression scale. An updated literature review. J Psychosom Res 2002;52:69-77.

47 Wittchen H-U, Höfler M, Gander F, et al. Screening for mental disorders: performance of the composite international diagnostic screener (CID-S). Int J Methods Psychiatr Res 1999;8:59-70.

48 Wahl I, Löwe B, Bjorner JB, et al. Standardization of depression measurement: a common metric was developed for 11 self-report depression measures. J Clin Epidemiol 2014;67:73-86.
49 Schmidtmann I, Elsasser A, Weinmann A, et al. Coupled variable selection for regression modeling of complex treatment patterns in a clinical cancer registry. Stat Med 2014;33:5358-70.

50 Statistisches Bundesamt. Verdienstunterschied zwischen Frauen und Männern 2018 unverändert bei 21 \% [Internet]. Statistisches Bundesamt, 2019. Available: https://www.destatis.de/DE/Presse/ Pressemitteilungen/2019/03/PD19_098_621.html [Accessed 30 Nov 2019].

51 Luy M. Regionale Unterschiede [Internet]. Lebenserwartung in Deutschland, 2019. Available: https://www.lebenserwartung.info/ index-Dateien/regdiff.htm 